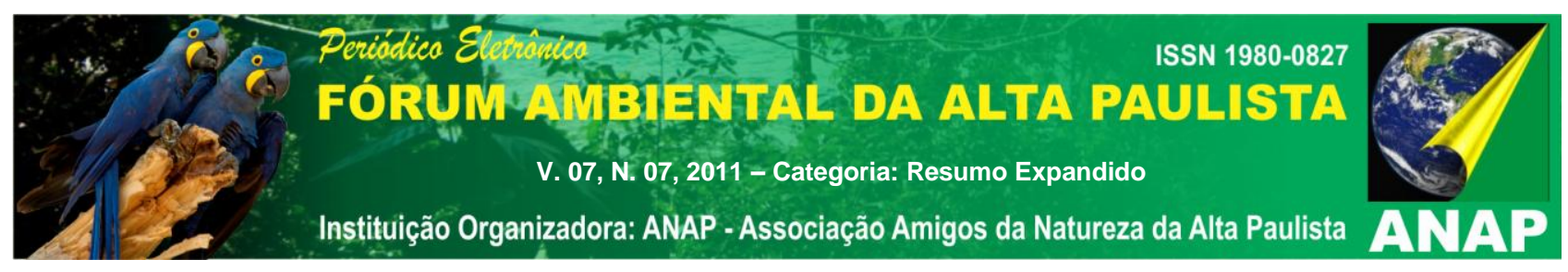

Titulo do Trabalho

\title{
TERRITÓRIO E A RELAÇÃO CIDADE-CAMPO E DESENVOLVIMENTO RURAL: CINTURÃO VERDE ILHA SOLTEIRA
}

Nome do Autor (a) Principal

Allain Wilham Silva de Oliveira

Nome (s) do Orientador (a) (s)

Rosângela de Medeiros Hespanhol, Antonio Nivaldo Hespanhol

Instituição ou Empresa

UFV e UNESP-FCT campus Pres. Prudente

E-mail de contato

allain@ufv.br

1) INTRODUÇÃO

Aspecto importante da estrutura do espaço geográfico, a localização foi essencial para a constituição de Ilha Solteira, quer seja pela existência de um quadro natural, com ênfase à disponibilidade hídrica, ou pela proximidade do centro geoeconômico do espaço brasileiro (Dourado, 2007). Assim, a relação cidade-campo e o desenvolvimento rural, na cidade de Ilha Solteira, devem ser observados na peculiaridade desse espaço, que é a sua gênese e evolução; uma vila construída para servir de apoio para a construção da hidrelétrica de Ilha Solteira, que faz parte do complexo de Urubupungá

Os aspectos históricos nos remetem às políticas de construção do complexo de Urubupungá e à formação da vila, já com o objetivo de se tornar uma cidade. Esse projeto nos mostra as ações sociais que o constituem, por meio de técnicas, com o objetivo de formação de uma configuração socioespacial específica Pode-se concluir que a constituição de Ilha Solteira não é apenas um suporte para aumentar a produtividade do 


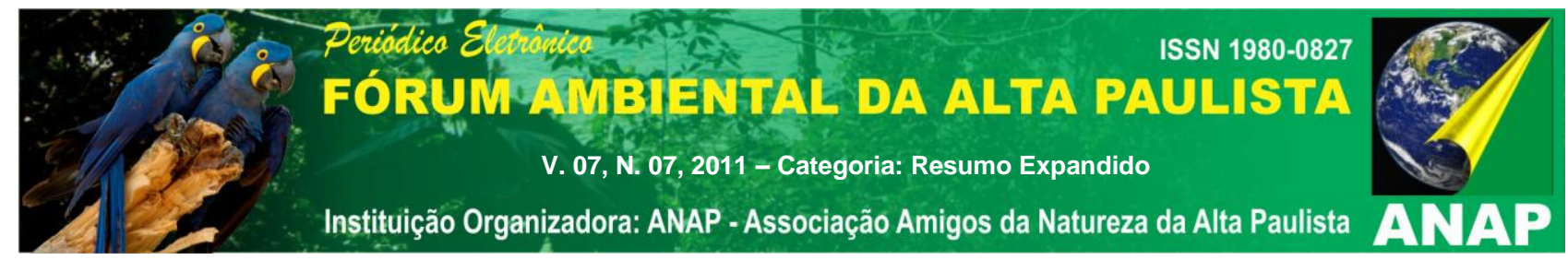

sistema elétrico brasileiro, mas também existe uma intencionalidade inserida dentro de uma estrutura e de um processo histórico de constituição de uma urbanidade e ruralidade com diversos elementos interdependentes, tais como moradia, serviços, produção agrícola, circulação e gestão.

Com a presença do estado, via CESP, é criada também uma área rural. Como perspectiva aponta-se projetos diferenciados, em que se cria um projeto para promover o reassentamento da população por meio de arrendamento, "concessão onerosa de uso". Esse projeto ficou conhecido como Projeto Cinturão Verde de llha Solteira. O trabalho de Muitos agricultores perderam suas terras com o processo de enchimento do lago e a seleção se deu entre os moradores locais. Podemos observar, integrada ao planejamento de Ilha Solteira, mas já com sua origem atrelada a todo processo de formação deste espaço, uma forma de dar características próprias ao lugar, com uma lógica técnica e funcional de criar um território articulado e perfeito, um ideal técnico. Todos pretendiam liquidar o passado e realizar um ideal, a cidade na qual a lógica sobreporia aos males da não organização e do caos.

A Associação dos Pequenos Agricultores do Projeto Cinturão Verde de llha Solteira, instituição representativa dos agricultores assentados no Projeto Cinturão Verde, mediadora de interesses e captadora de recursos, foi criada por ação da CESP, por meio de reuniões de vizinhanças em curto espaço de tempo, denominado grupalização. Pela iniciativa da empresa estatal CESP, percebe-se o surgimento de uma pequena autonomia, mas com sua retirada, depois da implantação do município de Ilha Solteira, observou-se o aumento do poder municipal na associação. Podem-se relatar diversas políticas públicas com a intermediação do município, de grupos políticos externos à associação, ou mesmo de vereadores, tais como: Diagnóstico Rural Participativo, prorurisa, Programa Estadual de Microbacias Hidrográficas, Associação de Máquinas APPCUls, entre outros. Assim, pelo texto, percebe-se a existência de trocas de benefícios que ampliam a dependência dessa associação do poder público, reforçando a sua pequena autonomia (Moraes, $\mathrm{s} / \mathrm{d}$ ).

A estruturação espacial e o seu ordenamento levam em consideração as relações internas e externas no espaço llha Solteira e o Cinturão Verde é um representante dessas relações, no qual trabalhamos com a proposição de que, como todo projeto, ele nasce com uma forte interferência do poder público, desde o planejamento inicial, recrutando os 


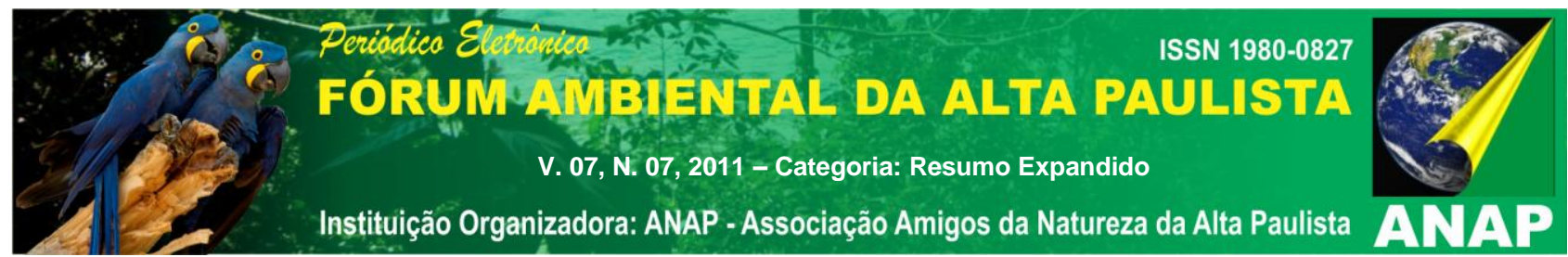

moradores e gestão. O Cinturão Verde, criado pela CESP e administrado pela associação, também depende da Prefeitura, assim, criaram-se rugosidades que ainda permanecem e são elas que marcam a relação cidade-campo e o desenvolvimento rural. Entendemos o conceito de rugosidade como sendo formas preteridas de espaço que influenciam a atualidade, segundo Santos (2009):

"chamemos rugosidade ao que fica do passado como forma, espaço construído, paisagem, o que resta do processo de supressão acumulação, superposição, com que as se substituem e acumulam em todos os lugares. As rugosidades se apresentam como formas isoladas ou arranjos. É dessa forma que elas são uma parte desse espaço-fator. Ainda que sem tradução imediata, as rugosidades nos trazem os restos da divisão do trabalho Já passadas (todas as escalas da divisão social do trabalho),os restos dos tipos de capital utilizados e suas combinações técnicas e sociais"(Santos, 2009, pag. 140)

\section{2) OBJETIVOS}

As rugosidades espaciais são a conexão material do presente. O processo já realizado entende que os fixos são econômicos, sociais, culturais e fluxos deriva de sua qualidade e do seu peso político medido pela técnica (Santos, 2009), assim um novo espaço surge já influenciado pelo anterior. No caso de Ilha Solteira, não apenas os objetos, como a distribuição e ordenamento do espaço e sua segmentação estão presentes na paisagem, e mesmo os fluxos, ou seja, a forma de estabelecer relações próprias para o processo de desenvolvimento do território, no caso o Cinturão, continua influenciada pelas relações do início, tentando evidenciar a continuidade espaço-temporal, Com isso, espaço e sociedade vivem uma metamorfose "limitada"?

\section{3) METODOLOGIA}

Entendemos o trabalho de campo como uma metodologia de pesquisa, nesse caso, qualitativa, pois além de facilitar a visualização e assimilação de conceitos expostos de forma didática, ele é uma forma de conseguirmos a aproximação com o objeto de estudo, no caso a disciplina, bem como criar novos conhecidos a partir da realidade 


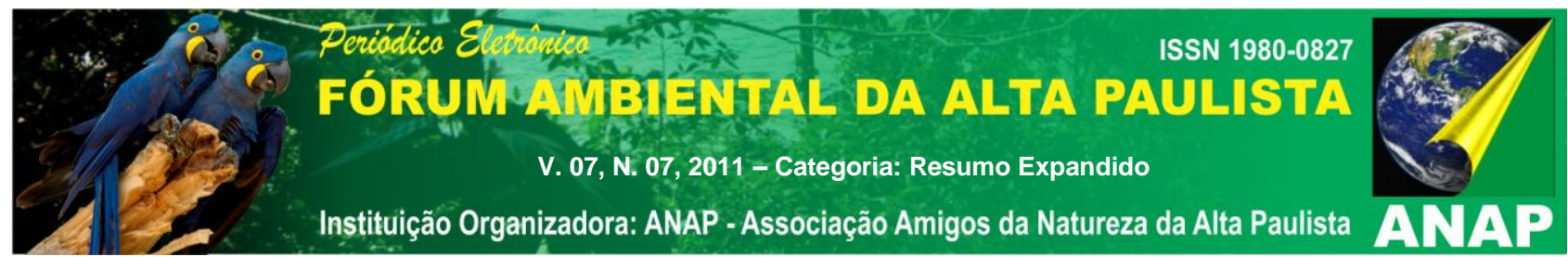

(Minayo, 2000). Assim, mediado por outras técnicas, como reunião, observação direta, contato com as famílias, registro da paisagem, entrevistas, caderno de campo, gravações e fotografias, o trabalho no campo se torna um elemento didático e de produção da ciência, o que possibilita o acréscimo de teoria e métodos ao que já foi observado.

A análise proposta para realizar nossas representações sobre o Cinturão Verde será baseada nas exposições colocadas em uma reunião entre os participantes do trabalho de campo com o extensionista rural da prefeitura e o presidente da Associação dos Produtores do Cinturão Verde, na qual fizemos uma "rodada de perguntas" e foram expostas ao grupo as dificuldades enfrentadas pelos agricultores do cinturão e mesmo de outras ruralidades de llha Solteira, como os assentados da reforma agrária. A entrevista foi gravada e a partir dessa gravação vamos analisar as falas dos agentes locaisenvolvidos, do presidente da Associação e do extensionista da prefeitura, com a intervenção do professor da UNESP, campus de Ilha Solteira, que acompanhou o trabalho.

A entrada em campo exige muitas atenções, pois muitas vezes não serve para confirmar tudo aquilo que julgamos saber, mas aponta para novas realidades. Cabe ressaltar aqui o contexto de uma reunião na qual já havia o conhecimento prévio dos atores que participariam e que representavam lideranças, mas não a totalidade do grupo Além do trabalho de campo, que colocamos no rol da metodologia, usaremos para interpretar a reunião a técnica chamada observação participante (Minayo, 2000). Eu, como participante, usei um gravador para detectar a forma como fui recebido, observei o grau de disponibilidade de dados, a postura adotada pelos participantes durante a reunião, os gestos, sinais corporais e, ou, mudanças de tom de voz, etc. Esses dados forneceram elementos para a interpretação e observação do fenômeno apresentado

\section{4) REFLEXÕES SOBRE O CINTURÃO VERDE}

A partir das observações feitas na reunião e da visita ao sítio urbano, a UNESP, podemos levantar algumas conclusões a respeito do Cinturão Verde de llha Solteira. A primeira noção é a de que estamos falando não de um rural oposto ao urbano, Assim, uma realidade que caracteriza o fenômeno rural Cinturão Verde é polissêmico, muitas vezes confundido com o agrícola, o que não representa uma verdade no mundo atual, 


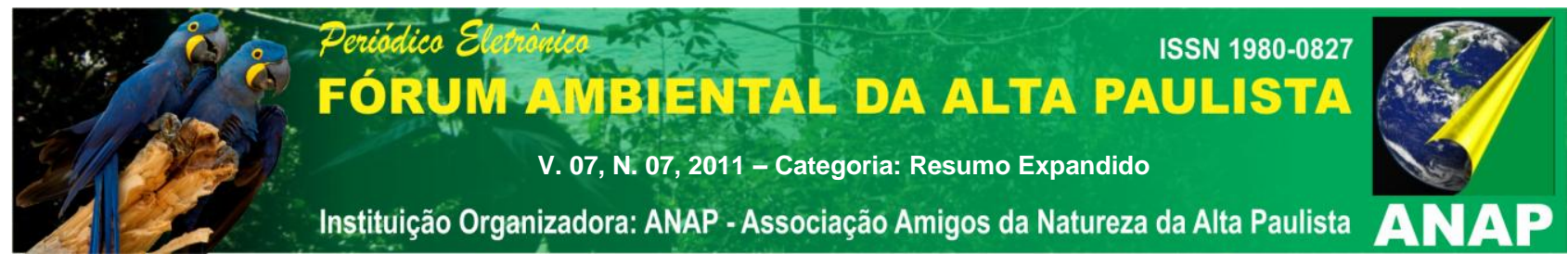

basta observarmos o Peri-urbano ou as áreas rurbanizadas. Como podemos observar pela forte ligação entre a questão do abastecimento local e mesmo da especulação imobiliária (Peri-urbano) sobre o Cinturão Verde, em muitos casos os lotes já foram transformados em moradias, assim, espaços rurbanizados, sendo também engendrados por relações sociais de gestão e formação desde a origem.

Como surgiu no campo, São Paulo, por ser um centro concentrador distante, imporia o fim da agricultura de llha Solteira? A entrada em campo é reveladora quando surge a questão da localização, como: "aqui é fim de linha, não tem onde colocar o produto", que, como empecilho ao desenvolvimento, faz retornar questões já superadas pelos estudos acadêmicos, como a questão de ordem natural, a irrigação em uma área vizinha ao lago da represa de llha Solteira. Será que precisaríamos retomar os estudos de Von Thunen,

Obviamente, o fator localização e natureza (água) não devem ser desprezados, mas a localização de llha Solteira não é no tempo e espaço a proposta por Thunen, pois ele estaria propondo uma teoria em uma época cujo transporte era precário em um estado isolado, com uniformidade de condições naturais, mesma tecnologia, e uma concorrência perfeita. Ele formaria círculos concêntricos de produção ao redor de uma cidade, mas é obvio que a região em estudo não é o elemento a superar, nem a questão principal para o desenvolvimento. A própria especulação imobiliária para fins de moradia, pela qual passa o Cinturão Verde, nos revela a não validade da teoria, pois estas terras seriam altamente valorizadas e estariam no principal círculo para a produção agrícola, já que a cidade funcionaria como único mercado.

Então estaria na natureza a questão. A água estaria no arenito e sua cobertura pelo basalto seria uma impossibilidade para a obtenção de água para irrigação, assim como o forte calor de verão; logo, estaríamos voltando ao determinismo geográfico. É irônico o fato de a cidade ter surgido pela disponibilidade hídrica e ter título de estância turística pelas praias do lago e agora a água se tornar o problema. É evidente que a localização e a natureza não são sérios problemas enfrentados na relação cidade-campo e desenvolvimento. No nosso caso de estudo, considero-as como conseqüência de outros fatores a serem considerados, e um deles está na relação histórica desse espaço.

O que mais se destacou na entrevista foi a visão paternalista, de assistencialismo por parte da prefeitura em relação aos agricultores do Cinturão, o que foi por diversas 


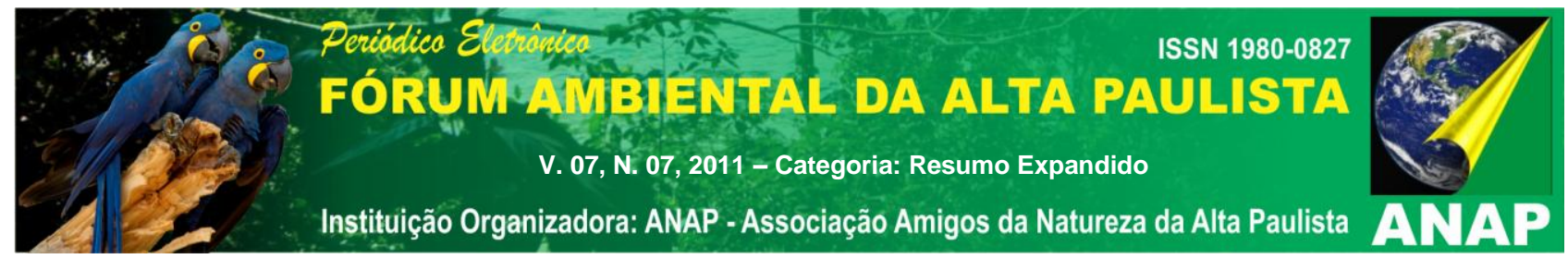

vezes confirmado, tanto pela postura do representante municipal como pela sua fala e pela fala do presidente da Associação, que no final se mostrou muito otimista. Esse tipo de intervenção, que já caracterizamos como uma rugosidade desse espaço, pois desde sua gênese ela está presente, leva a uma ação setorial agrícola e não a uma interferência territorial que necessitará de mudanças, que gerará o pouco sucesso do agricultor, mas o que de certa poderíamos dizer o não desenvolvimento territorial em llha Solteira, que Oliveira (s/d) chama de políticas do tipo top-dow .

\section{5) CONSIDERAÇÕES FINAIS}

Nas últimas décadas, a Geografia ampliou seu aparato metodológico e teórico que reflete a procura de sua eficiência científica. Recentemente, algumas linhas destacam a territorialidade nas interpretações do espaço, e é nesta leitura que podemos romper com a inércia territorial, com a implantação de políticas de participação e, em especial, levando em consideração que desenvolvimento deve ser pensado além do agrícola, em uma articulação entre a totalidade da sociedade que compõe o território Ilha Solteira. Seria uma forma de superar uma metamorfose "limitada", como observamos na perspectiva negativa por parte do poder público municipal, com intervenções apenas setoriais, sem vislumbrar a sustentabilidade territorial.

Podemos observar que existem questões além da esfera local, mas que ela reforça com interferência de ações localizadas, setoriais e paternalistas e que na história muda de "lugar", passando da CESP para poderes públicos (prefeitura, grupos políticos). Esse tipo de intervenção não traz a emancipação do grupo. A associação depende de relações clientelistas que dificultam o avanço do desenvolvimento. A emancipação do município trouxe uma pequena independência, garantindo em alguma escala a modernização, como a introdução de máquinas agrícolas. Mas a sociedade fica sem forma de expressão, incapaz de produzir modificações no seu território.

Ao finalizar nossa análise sobre a relação cidade-campo e desenvolvimento rural do caso Cinturão Verde de Ilha Solteira, vislumbramos que a superação de um modelo setorial de intervenção no espaço possibilitará a criação de elementos capazes de 


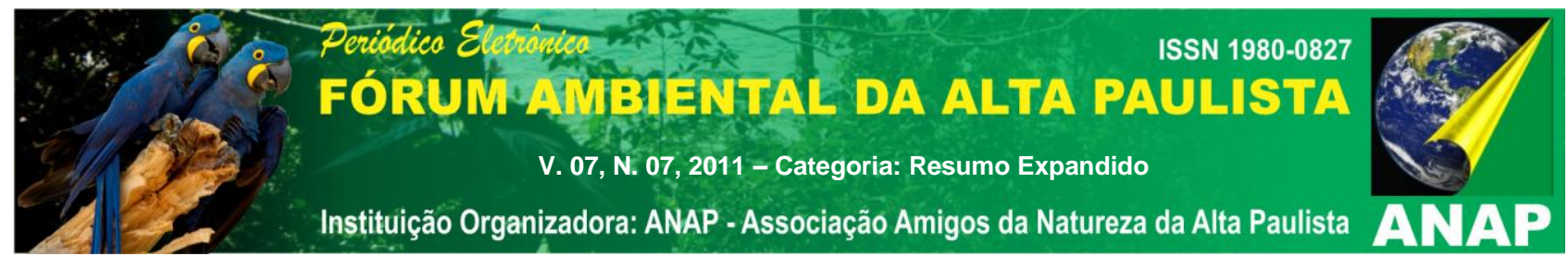

promover o seu desenvolvimento. Na visão de Oliveira (2002), uma inversão de lógica na política, a implantação de um modelo bottom-up, ou seja, pensada a partir da realidade econômica, social, cultural e institucional de determinado espaço. Podemos observar que Oliveira não abandona as características do local, mas a partir delas ele propõe mudanças. Ao buscar um elemento capaz de superar o setorial, no mesmo movimento, surge uma concepção renovada de território e territorialidade e de desenvolvimento que respeita as contradições, o crescimento, a história, a dialética socioespacial, os sujeitos locais, a atuação da política, a cultura e o meio ambiente (Saquet, 2008), produzindo a articulação necessária da política nas dimensões espaciais: ambiental, cultural, demográfica, urbana, rural e regional, com respectivos instrumentos.

\section{REFERÊNCIAS}

DOURADO, L.A.C. O espaço público e a territorialidade do lazer na estância turística de Ilha Solteira - SP. Aquidauana, MS. 2007, 135 f. Dissertação de mestrado em Geografia - Universidade Federal de Mato Grosso do Sul, Campus Aquidauana, p. 61-86.

MINAYO, C. S. et. al. Pesquisa Social: Teoria, Método e Criatividade. 15 a ed. Petrópolis, RJ: Vozes, 2000. 67 p.

MORAES, C. A. A.; ROSÂNGELA, R.; BARONE, L. A.; TARSITANO, M. A. Autonomia e Dependência na Associação dos Pequenos Agricultores do Projeto Cinturão Verde de Ilha Solteira. Faculdade de Engenharia de Ilha Solteira. Ilha Solteira. SP. (S/D).

OLIVEIRA, R. O. Desenvolvimento, Política Agrícola e Política Rural: do Setorial ao Territorial. Informações Econômicas, SP, V.32, 2002, p. 7-16

SANTOS, M. A natureza do espaço técnica e tempo, razão e emoção. 4⿳亠丷a ed. São Paulo. EDUSP. 2009. 377 p.

SAQUET, M. A.; SPOSITO, E. S. Território, Territorialidade e Desenvolvimento: Diferentes Perspectivas no Nível Internacional e no Brasil. In: Alves, A. F.; CARRIJO, R. B.; CANDIOTTO, L. Z. (Org). Desenvolvimento Territorial e Agroecologia. SP: Expressão Popular, 2008, p. 15-32. 